\title{
Peanut oil and peanut allergy, foes or folks?
}

Peanut allergy (PA) has become a major health concern, but the reasons for this increasing prevalence are not well understood. ${ }^{1}$ Although the consumption levels of peanuts in the USA and China are similar, the rate of PA was believed to be much lower in China. ${ }^{1}$ Hong Kong is one of the most Westernised city of China, and the prevalence in atopic disorders such as asthma, allergic rhinitis and atopic eczema were comparable with most developed countries; yet PA was rarely encountered in the past decades until recently. A recent study showed a prevalence of PA of $0.52 \%-0.65 \%$ in preschoolers. ${ }^{2}$ We speculate that this could be related to changes in diet and culture over the past decades. Crude peanut oil is ubiquitous in maternal and infant diet in Hong Kong in the past. Available data suggest that the protein content of crude oils is of the order of 100$300 \mu \mathrm{g} / \mathrm{ml}$ and that of the refine type is at 100 -fold lower. ${ }^{3}$ We studied the longitudinal trend of edible peanut oil (1980-2007) in our population. The study period constituted major political, cultural economic and lifestyle changes of the population. Hong Kong has little arable land and few natural resources, so it imports most of its food including edible oils and raw materials. Data of the import and re-export oil was obtained from the merchandise trade statistics department. The consumption of edible oil was estimated from imports subtracted with re-exports. The population data was provided by the census and statistics department. The annual edible oil consumption per capita was calculated, and time trend was also analysed by simple linear regression. The trends of various edible oils consumptions were summarised in figure $1 \mathrm{~A}-\mathrm{F}$. The annual consumption per capital basis of total peanut oil had decreased twofold to threefold. The crude type had almost 30-40-fold decrease, whereas there was not much change for the refined type. The estimated equivalent peanut protein ingestion through crude peanut oil reduced from $28.8 \mathrm{~g}$ to less than $1 \mathrm{~g}$ weekly per capita. In contrast, there was a 30 -fold increase in annual consumption per capita of olive oil. The annual consumption of other types of oils fluctuated widely.

Peanut oil has been implicated as one of the aetiology factors of PA. Allergic 


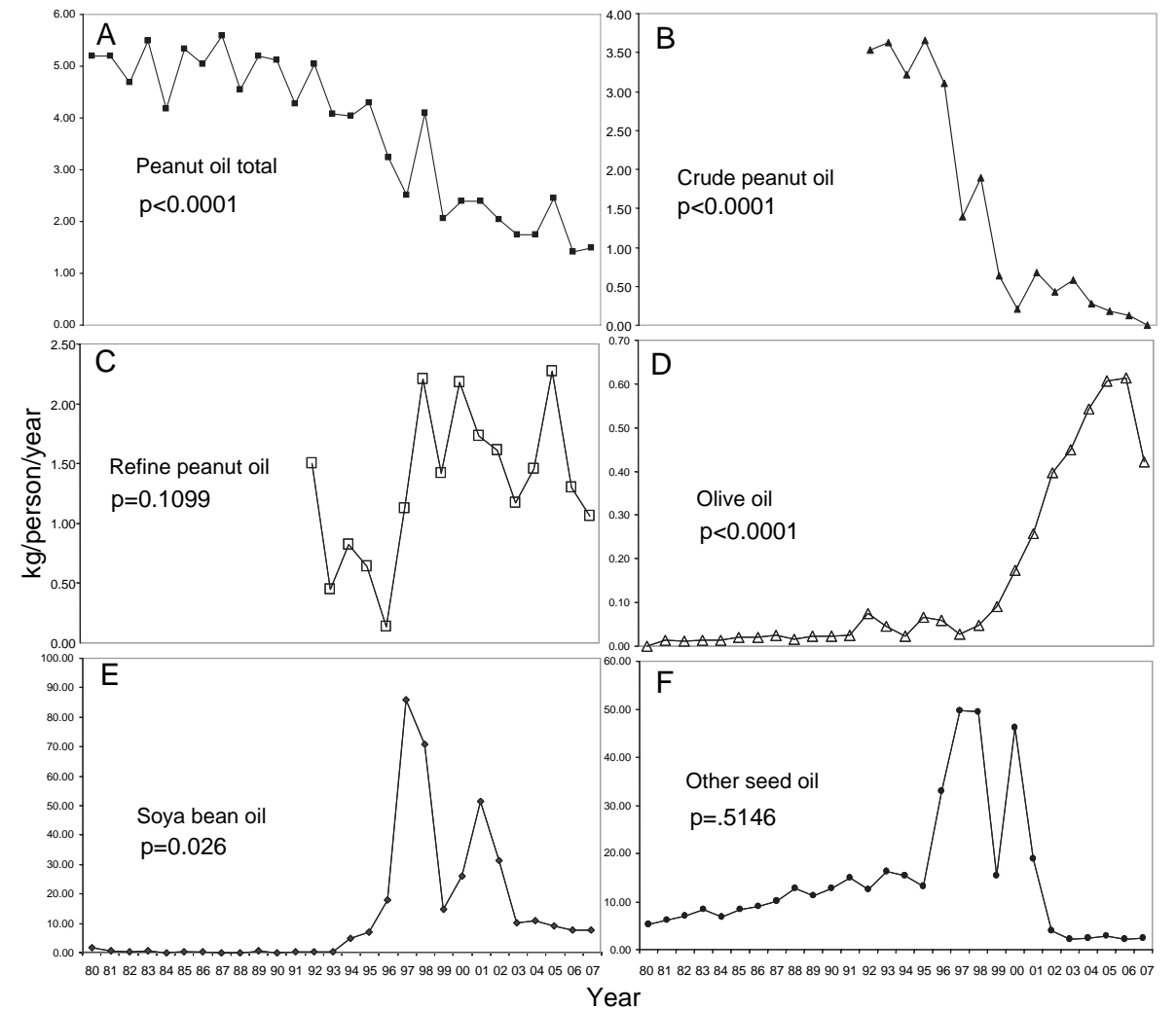

Figure 1 Annual consumption of edible oils per capita in Hong Kong (kilogram/person/year).

reactions to peanut oil, though infrequent, are well recognised in highly sensitised subjects. The odds ratio for peanut sensitisation was significantly higher in infants who had received vitamin D supplements in peanut oil than in control. ${ }^{4}$ Sensitisation to peanut protein occurred in children through the application of peanut oil to inflamed skin. ${ }^{5}$ However, peanut oil as a foe may not be the entire story. It is gaining consensus that avoiding consumption of peanut abrogates development of oral tolerance and increases risk of hypersensitivity through cutaneous exposure. The timing, perhaps the dosage and the balance of cutaneous and oral exposure determine whether a child will have allergy or tolerance. Crude edible peanut oil contains immunogenicity-competent protein fractions that may deserve further studies on its implication on PA prevention at population level. We hypothesise in our population that it has been acting through low-dose tolerance mechanism by the minute protein fractions of peanut oil that synergise the high-dose tolerance when a child reaches the age of formal ingestion of peanut.
A reverse ratio of consumption of peanut/olive oil may serve as a surrogate of Westernisation in diet, worthy to be verified in other populations.

\section{H K Ho, S Lee, W H S Wong, Y Lau}

Department of Paediatrics and Adolescent Medicine, Queen Mary Hospital, The University of Hong Kong, Hong Kong, People's Republic of China

Correspondence to Dr Marco H K Ho, Department of Pediatrics and Adolescent Medicine, Queen Mary Hospital, The University of Hong Kong, Pokfulam, Hong Kong, People's Republic of China; marcoho@hkucc.hku.hk

Competing interests None.

Provenance and peer review Not commissioned; internally peer reviewed.

Accepted 30 April 2010

Arch Dis Child 2010;95:856-857.

doi:10.1136/adc.2010.190637

\section{REFERENCES}

1. Ho MHK, Lee SL, Wong WHS, et al. Peanut allergy. Lancet 2008;371:1538-46.

2. Leung TF, Yung E, Wong YS, et al. Parentreported adverse food reactions in Hong Kong
Chinese pre-schoolers: epidemiology, clinical spectrum and risk factors. Pediatr Allergy Immunol 2009;20:339-46.

3. Crevel RW, Kerkhoff MA, Koning MM. Allergenicity of refined vegetable oils. Food Chem Toxicol 2000;38:385-93.

4. de Montis G, Gendrel D, Chemillier-Truong M, et al. Sensitisation to peanut and vitamin D oily preparations. Lancet 1993;341:1411.

5. Lack G, Fox D, Northstone K, et al.; Avon Longitudinal Study of Parents and Children Study Team. Factors associated with the development of peanut allergy in childhood. N Engl J Med 2003;348:977-85. 